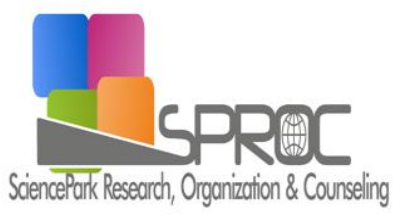

\section{Global Journal of Arts Education}

Volume 8, Issue 1, (2018) 28-45

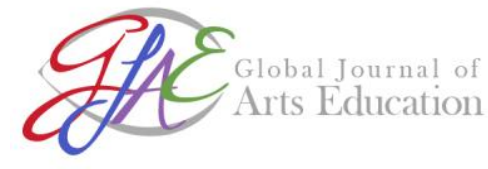

\title{
students' work
}

, Department of Architecture, Faculty of Architecture, Akdeniz University, Antalya, Turkey.

*, Department of Architecture, Faculty of Architecture, Suleyman Demirel University,

Isparta, Turkey.

Karakok, M. E. C. \& Gokarslan, A. B. (2018). A workshop experience in the intersection of design and conservation disciplines: Mediterranean architecture schools students' workshop. Global Journal of Arts Education. 8(1), 28-45.

Received from November 26, 2017; revised from December 18, 2017; accepted from January $02,2018$.

Selection and peer review under responsibility of Prof. Dr. Ayse Cakir Ilhan, Ankara University, Turkey.

${ }^{\circledR} 2018$ SciencePark Research, Organization \& Counseling. All rights reserved.

MASS'(Mediterra nean Architecture Schools Students') Workshop 2015 is jointly organised by the Department of Archi te cture of Suleyman Demirel University (SDU) and Akdeniz University, which was held from May 5-9, 2015 in Isparta. 60 students from SDU and 30 students from Akdeniz University were participated in this event. A main topic of this workshop is 'Conte mporary addition in the his toric context'. Isparta Uzum Bazaar and Koy Bazaar including two different historic areas have been studied. The two groups of students have designed top covers to the streets of these a reas. The workshop aimed to combine students' research and theoretical information; and also, develop conversion skills of design projects. Thus, the workshop draws theory-research-application bonds in the minds of students. It offers students free interaction and sharing, to gain group work experience, to provide intellectual connection and to develop thinking skills in short time. Fina lly, the MASS workshop eventimproved with participation from the diffe rent Mediterranean countries.

Keywords: Contempora ry addition in the historic context, a rchi tectural educa tion, Workshops. 
Due to high demands of the architecture students of Suleyman Demirel University (SDU) and Akdeniz University, a joint workshop was organised, bringing together junior students from both universities. Workshop organisation was named Mediterranean Architecture Schools Students (MASS) Workshop 2015 as an acronym for 'MASS' since both universities are in Mediterranean Region and its participants are architecture students. Organised first in 2015, MASS Workshop Event is aimed to be an annual event with participations from the architectural schools of other Mediterranean countries.

The focus of the workshop was envisioned to be based on a concept where students both get to use their preservation and renovation knowledge and create their own designs at the same time. Thus, the theme of the workshop was set as 'modern additions on historical structures'. The workshop was hosted by the Department of Architecture of SDU Faculty of Architecture. Therefore, two historical structures in Isparta that were known to need additional modern designs were chosen for design within the framework of the concept.

The historical bazaar known as Uzum Carsisi (Grape Bazaar) was chosen as one of the work areas. This historical place has a problem that sets the agenda in terms of architectural preservation in Isparta and this problem needs an urgent solution. Antalya Regional Directorate of Cultural Heritage made a decision to remove the subsequently made cover vaults over the streets of the bazaar and assigned the Municipality of Isparta to the project. However, the shopkeepers of the bazaar requested an injunction to the decision and stated that there was a need for the covers. Regional Directorate then answered the request of bazaar shopkeepers that 'It could be allowed only if there was a modem addition that doesn't damage the structures and the texture of the area'. Therefore, a need for covers that are modern, yet consistent with the historical texture of Uzum Carsisi became apparent.

The area known as Koy Pazari (Village Bazaar) is chosen for the second project. Koy Pazari is not an actual historical area, but it's a present-day shopping area located in a historical texture in a shed-like structure. Set up every day of the week, it creates a complicated view and makes the historical texture difficult to be perceived. On the other hand, sellers and buyers of the market are also directly affected by the rain, snow and extreme temperatures. Those who use the area on their routes, try to find their way between the chaoses of the bazaar. Thus, a decision was made to organise the bazaar area in a way that it doesn't disrupt its historical texture, visuals and integrity, to make walking routes clearer; and also, to design an upper cover structure that would allow people not to be affected too much by weather conditions. Two workshops have been created.

The focus of the workshop was envisioned to be based on a concept where students both get to use their preservation and renovation knowledge and create their own designs at the same time. Thus, the theme of the workshop was set as 'modern additions on historical structures'. Designing a covering structure over two of the historical textures of Isparta, the streets of Uzum Pazari and Koy Pazari were chosen for the concept of modem addition. Located at the intersection of 101 Street and 114 Street in Kaymakkapi Square, Uzum Pazari is found in the historical city centre of Isparta. Mimar Sinan Mosque is located to the north, the historical Kaymakkapi Square and 114 Street is found in the south, and today's small businesses to east and Mimar Sinan Street is located in the west. There are also Ottoman Era structures like Firdevs Bey Bedesteni (Firdevs Bey Bazaar), Dalboyunlu and Bey Turkish Bathhouses and Republican Era structures like the Government Office and Isparta Hotel in its vicinity (Figure 1). 


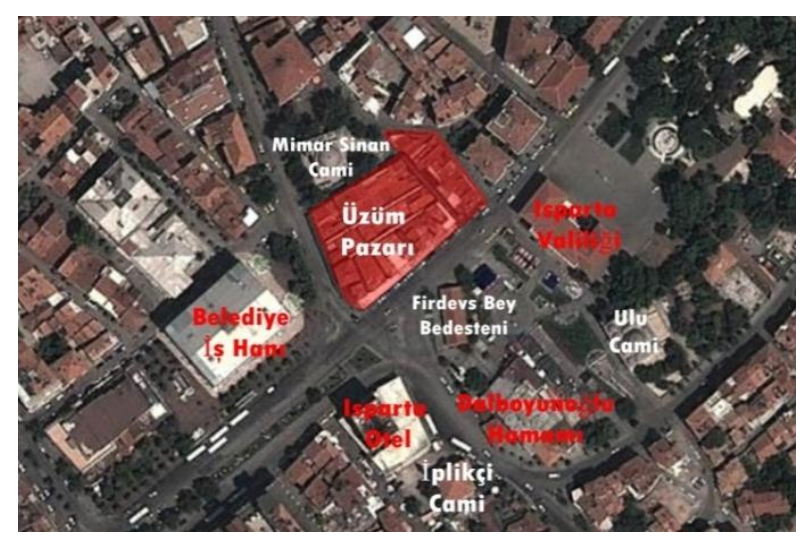

\subsection{Uzum Pazari (grape bazaar)}

Uzum Pazari is known to have been built in 1561 (Bocuzade, 1983). It has the features of a Classical Ottoman Era Turkish Bazaar (open bazaar). In the Ottoman Era, it was not only an important bazaar for Isparta, but it was also one of the most important bazaars in Turkey. Uzum Pazari generally consists of small, conjoined shops in narrow streets. The shops which we have no information about the period they were built-in have two or three floors each. Turkish and Greek shopkeepers worked together in the construction. The constructions of stone buildings are known to be made by Greeks, while the wooden buildings are constructed by Turks (Bocuzade, 1983).

According to the ordinance number 1495 on 28 July 1992 of Antalya Regional Directorate of Cultural and Natural Heritage, ${ }^{1}$ the area had been declared an urban protected site. With that decision, 16 of the 114 shops of Uzum Pazari are also registered. Registered shops were built with white clay stones called 'kovke', a local construction stone of Isparta; but wooden buildings that were mentioned by Suleyman Sami Bocuzade (1983) did not survive until today. All of the registered shops have two floors and one basement (Figures 2 and 3 ).

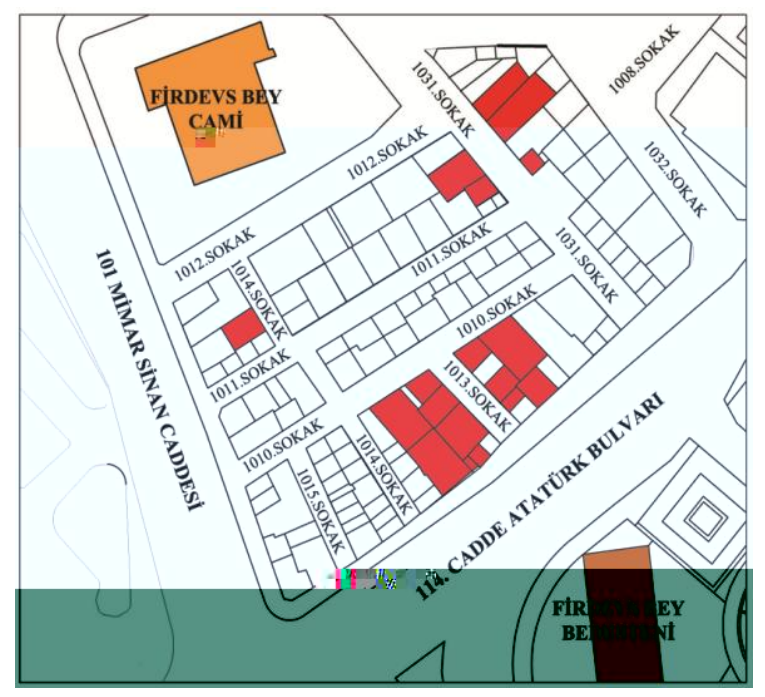

\footnotetext{
${ }^{1}$ Until 2011, the agency had 'natural heritage' in its name as it appeared in its respective ordinance documents; Antalya Regional Directora te of Cultural and Natural Heritage. After 2011, the agency had been referred to with its new name.
} 


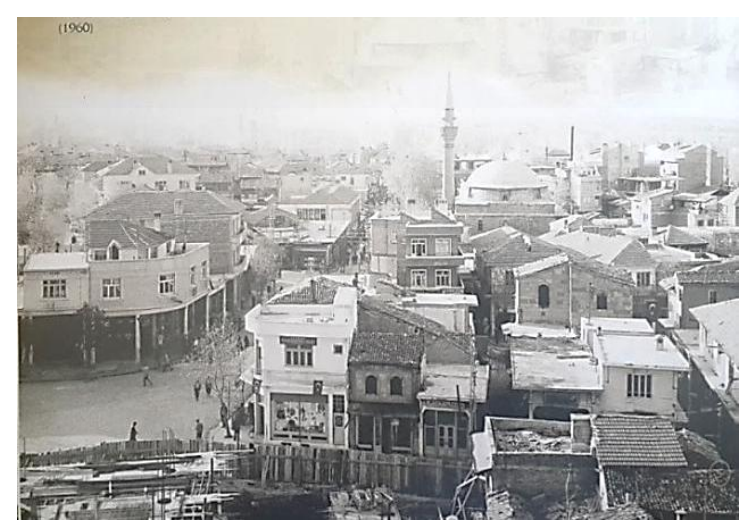

(Source: Isparta Governship, 2001)

In 1995, Municipality of Isparta covered over bazaars' streets and close areas using a covering system with funds from the shopkeepers without seeking permission from Antalya Regional Directorate of Cultural and Natural Heritage. This upper covering system has an elevation of the first and second floor levels and made from polycarbonate material with a vaulted from (Figure 4). With its decree no. 2010 on 13 December 2007, Antalya Regional Directorate of Cultural and Natural Heritage declared the area that also included Uzum Pazari section an urban protected site. And in the same decree, it also ordered Municipality of Isparta to remove the upper covering system found over the streets of Uzum Pazari and to create a streetscaping project for the bazaar.

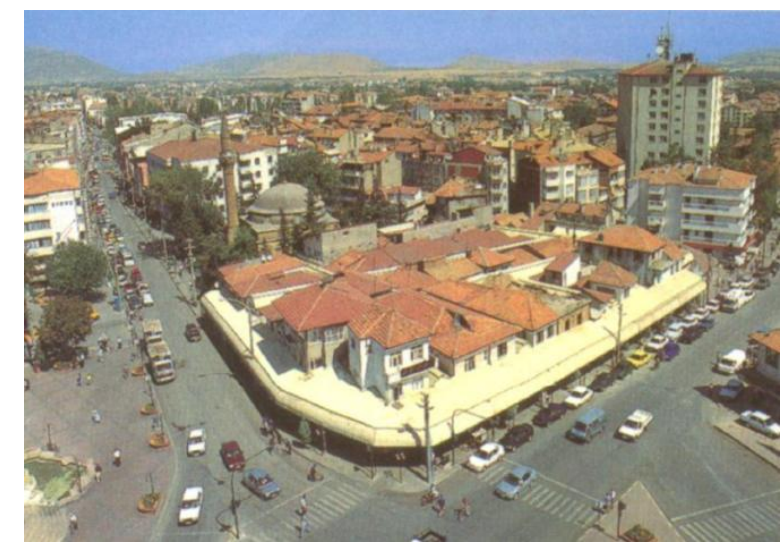

(Source: Isparta Municipality Archive, 2014)

The municipality of Isparta had created a streetscaping project for Uzum Pazari and this project had been approved by Antalya Regional Directorate of Cultural and Natural Heritage's decree no 2261 on 27 March 2008. According to this project, the shops had hipped roofs with tile linings, streets are lined with andesite stones and paving lights were installed on streets. However, the removal of the polycarbonate upper cover faced the criticisms of shopkeepers in the bazaar. Arguing that an upper cover was necessary for the purposes of exposing their goods to the buyers and the protection of clients from weather conditions while shopping, shopkeepers had requested from Antalya Regional Directorate of Cultural and Natural Heritage that not to remove the polycarbonate upper cover. Because of this request, Antalya Regional Directorate of Cultural and Natural Heritage declared Isparta Uzum Pazari a 'Special Project Area' and ordered Isparta Municipality to create and oversee a project 
that contains suggestions about the upper cover of Uzum Pazari. The search for a suitable upper cover for Uzum Pazari still continues today (Figure 5).
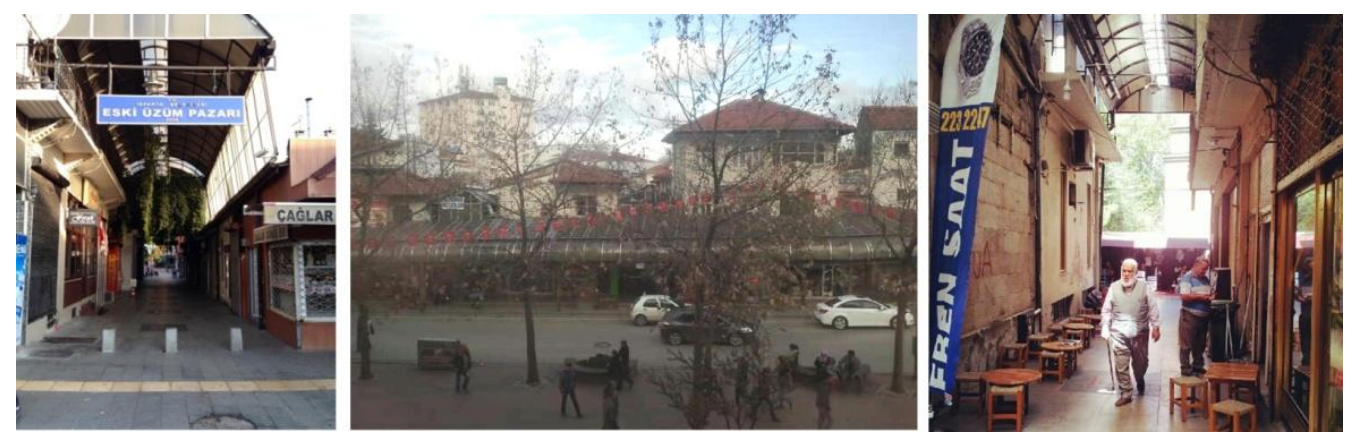

Koy Pazari is located on the city block that sits between 112nd and 121st Avenues on 1409 and 1410 Streets in the historical Kaymakkap square of Isparta city centre (Figure 6). Koy Pazari in itself does not have a direct, historical quality. The municipality of Isparta had brought the sellers who sold their products in different places of the city together in 2008 in this area, where it called 'Producers Market'. However, Koy Pazari sits in a 2nd degree urban and historical protected area of Isparta. Besides, 1410 Street where the bazaar is set up is on the list of 'Protected Streets of Isparta' in the decree of Antalya Regional Directorate of Cultural and Natural Heritage no. 1303 on 10 November 2006. The area also has a special location bordered by structures like Iplikci Mosque (1554-1569), which is one of the registered buildings of the city, Cumhuriyet Elementary School (1925) and Gazi Elementary School (19th century) and Isparta Hotel (1960). In its vicinity, there are also the important public buildings and civil architecture examples of Isparta like Firdevs Bey Bazaar (1561), Uzum Pazari (1561) and Dalboyunoglu Turkish Bathhouse (1693) (Demirgil, 2007). Because of these reasons, the area is an exclusive place for Isparta City (Figures 7 and 8).

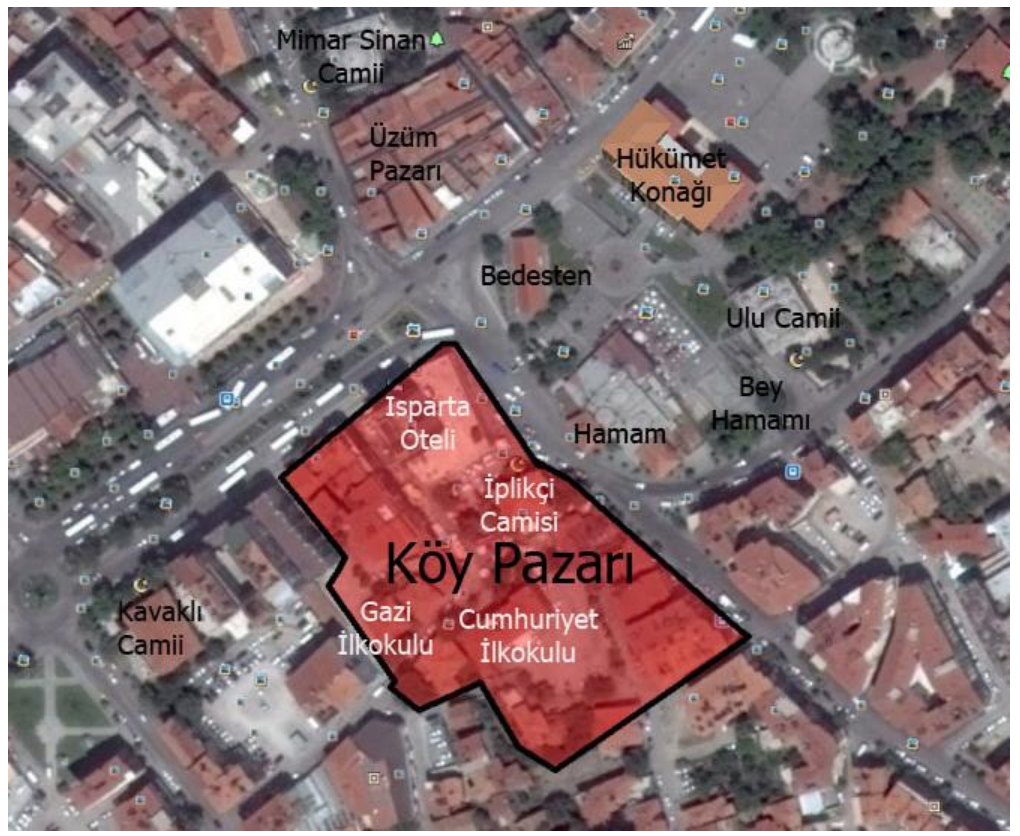




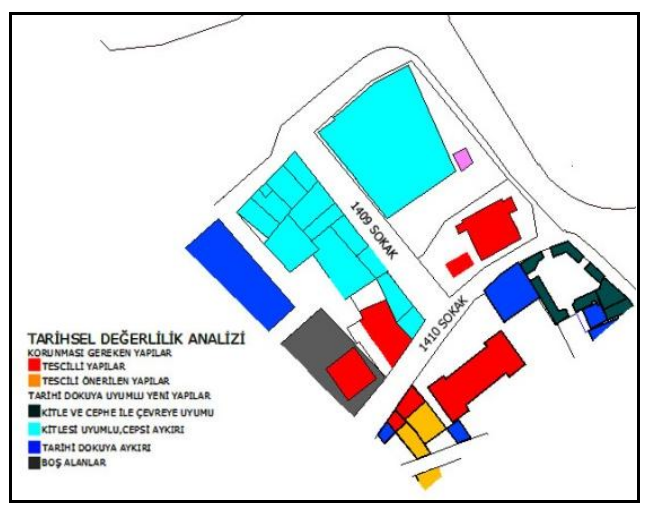

(Source: SDU, 2015)

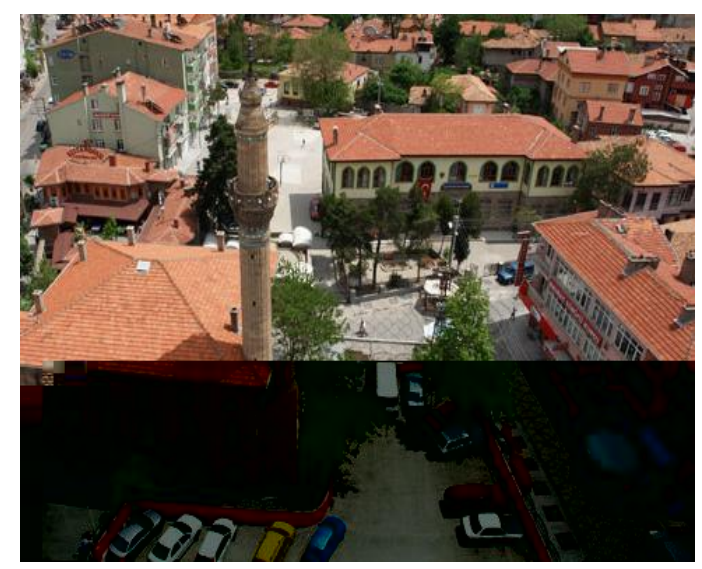

(Source: SDU, 2015)

While the Koy Pazari project of Isparta Municipality started as a way to organise the sellers who had set up shops in different parts of the city and to improve the overall look of the city in 2008, it failed to accomplish this goal. Because with today's situation, sellers are located in a cluttered and random way in the most important focus point of Isparta occupying two streets in a historical part of the city. This creates an ugly sight in a historical and special part of the city. Furthermore, different covers the sellers are using make it difficult to observe the historical structures and create a cacophonic environment. Considering the fact that Koy Pazari is used whole day, every day of the week and sellers even leave the produce, the stalls they use to sell them and upper covers on the market, it becomes clear that there is a constant visual pollution in the historical area (Figure 9).
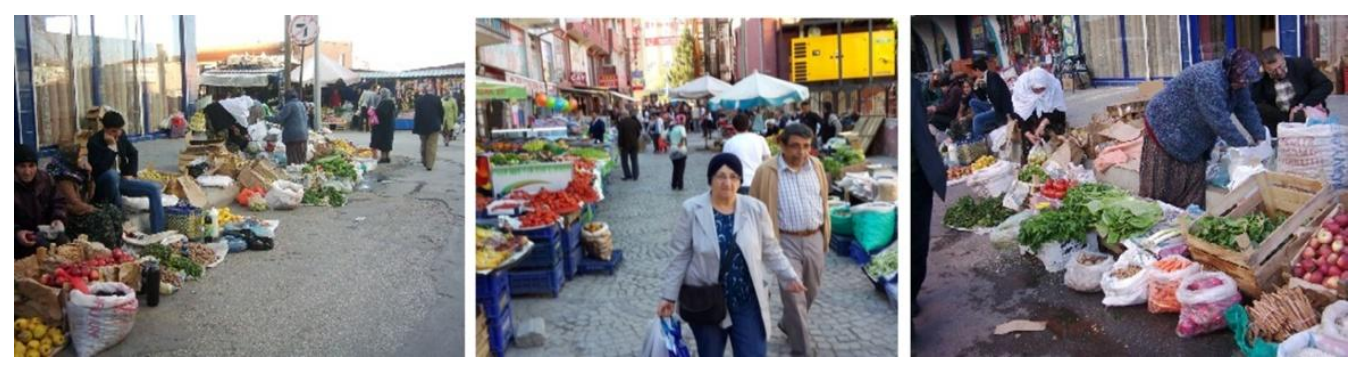


\subsection{Field analyses}

Analyses related to the protected areas outlined in the Reconstruction plan for protection of Isparta have been made within the scope of the 2014-2015 course, 'Awareness and Apprehension of Conservation' and detailed analyses of both areas have been made in MASS 2015 Workshop. Analyses like fullness-emptiness, the number of floors, usage type, ownership status, materials, durability, historical period, historical value, preservation status, environmental value and suggestions have been performed. In addition to these analyses, the area was also photographed, silhouetted and a report was drafted (Figures 10-13).

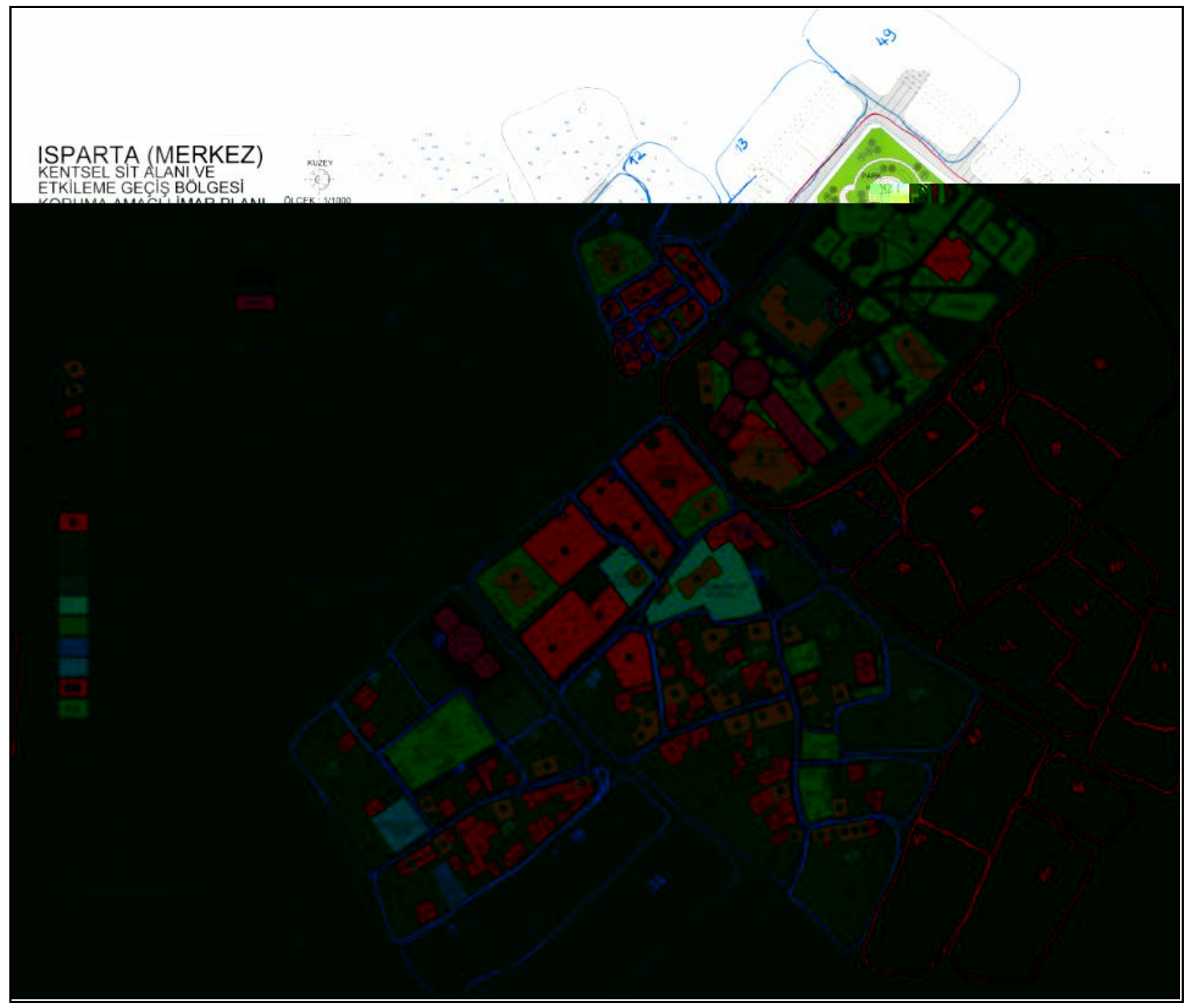




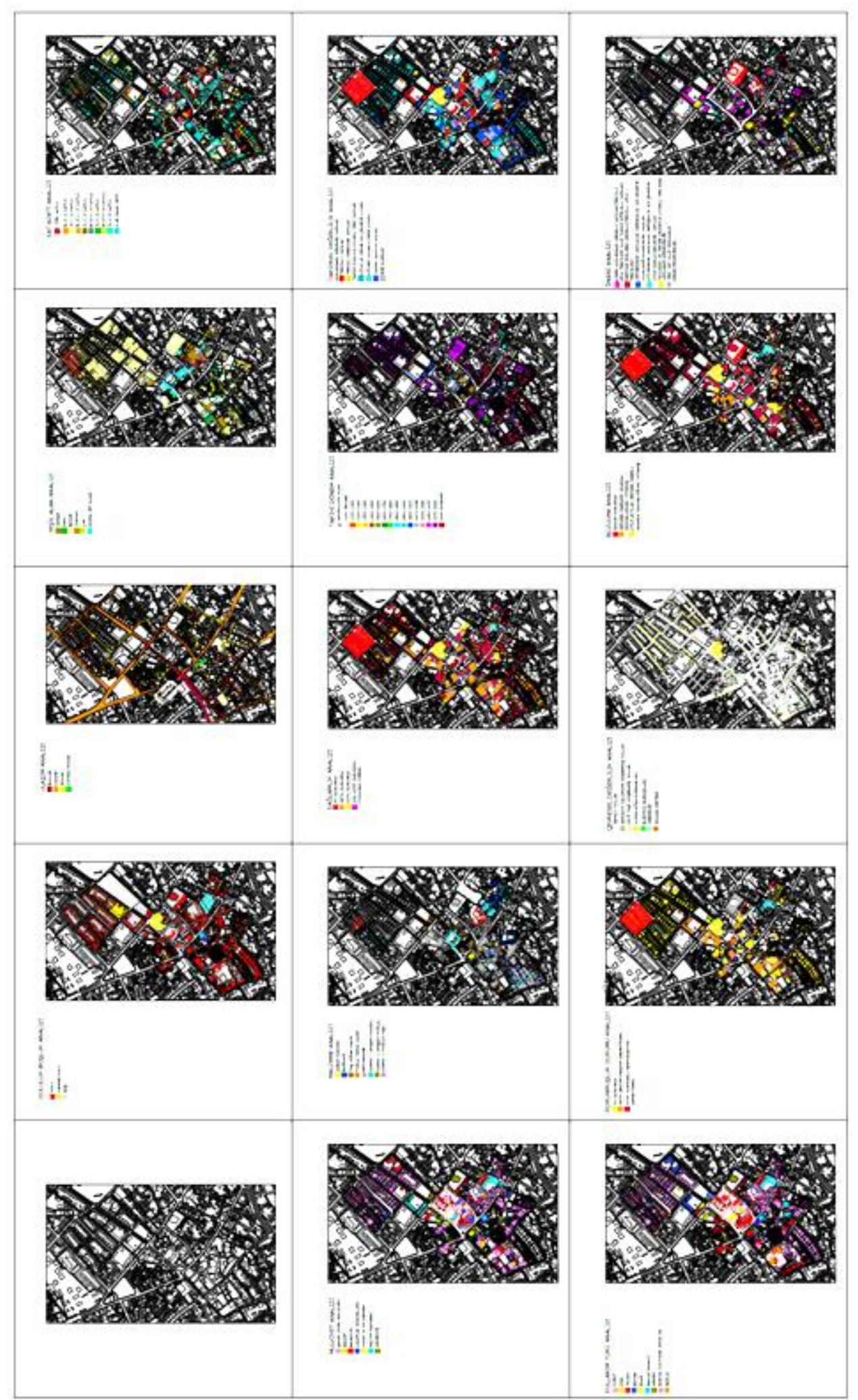

(Source: SDU, 2015) 
Karakok, M. E. C. \& Gokarslan, A. B. (2018). A workshop experience in the intersection of design and conservation disciplines: Mediterranean architecture schools students' workshop. Global Journal of Arts Education. 8(1), 28-45.

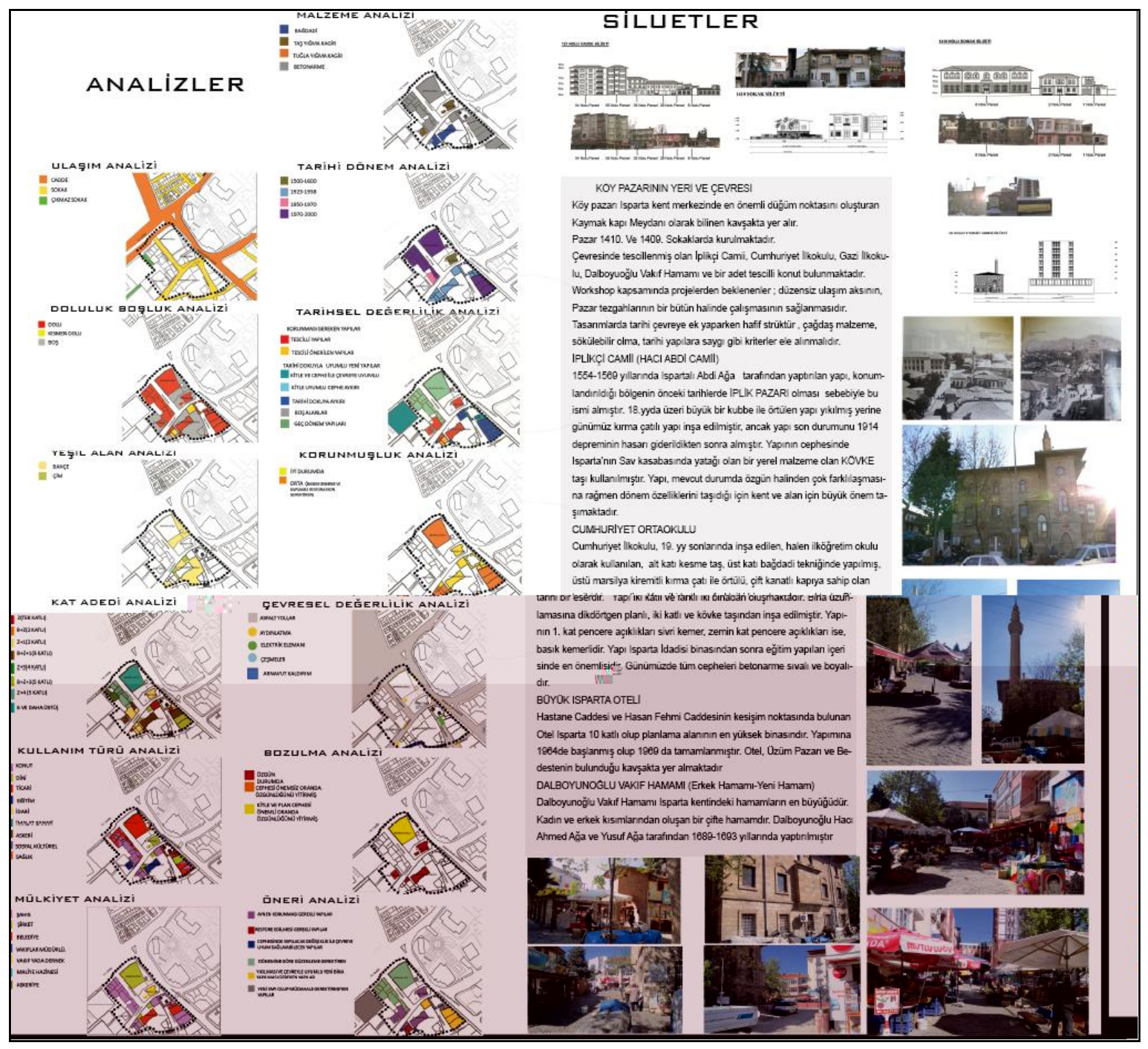

(Source: SDU, 2015) 


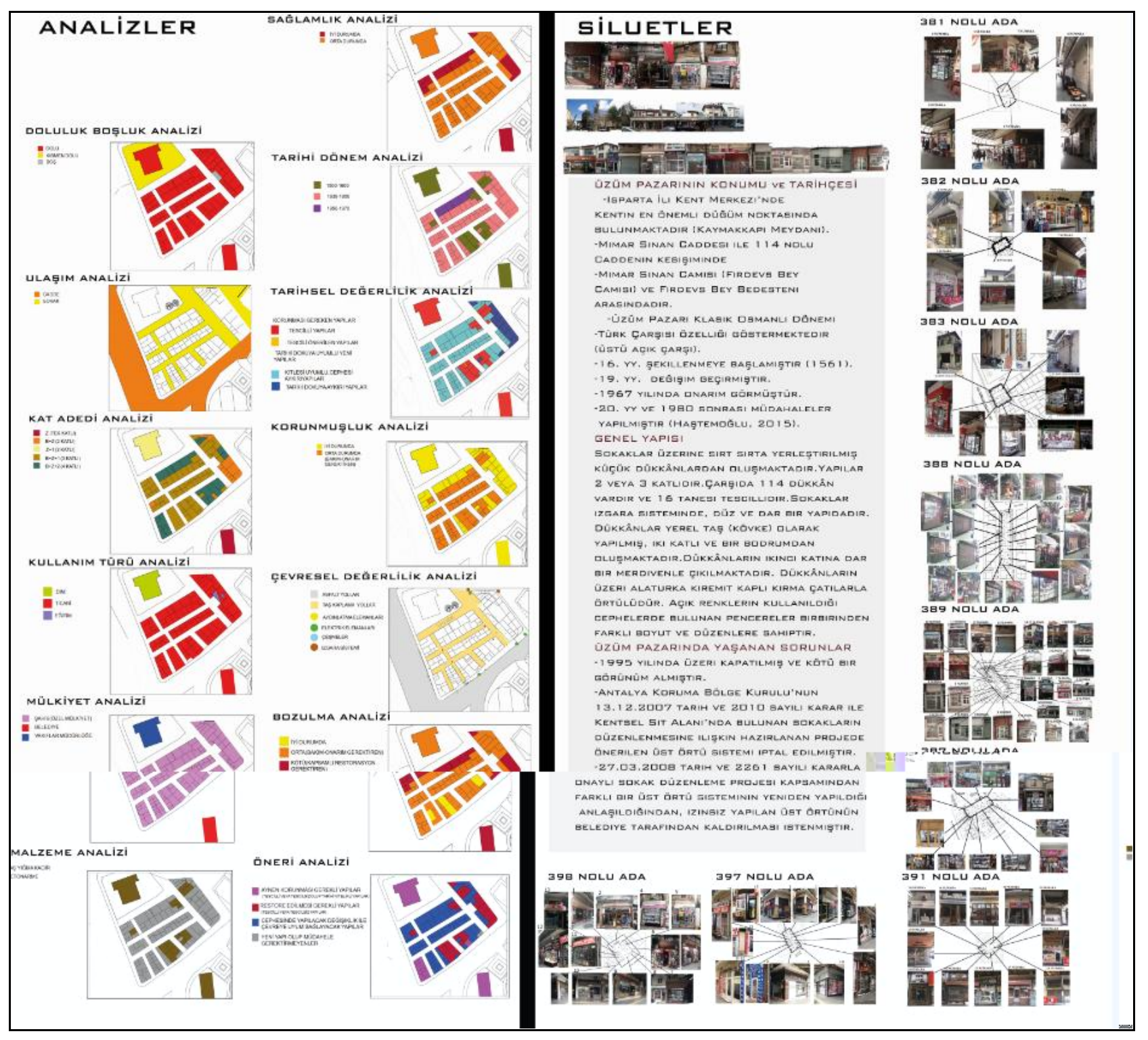

(Source: SDU, 2015)

In the first project area of the workshop event Uzum Pazari, the goal is to create upper sheets that can protect the streets of the bazaar from weather conditions. In the second project area of the workshop event Koy Pazari, the aim is to arrange seller stalls in an organised manner and to design an upper cover that can protect both the sellers and their produce from weather conditions. The main theme of the workshop event is based on 'modem additions to historical textures'. The students of the workshop groups are expected to create designs that can solve the aforementioned problems of both Uzum Pazari and Koy Pazari areas. 
Participating students of the workshop events are divided into eight groups. Four of those groups worked on Uzum Pazari while the other four worked on Koy Pazari area. Each group presented their projects with a report.

\subsection{First workshop project: Uzum Pazari project reports}

\subsubsection{Group project report}

The design of the upper cover was inspired by the concepts of fluidity, movement and motion in the streets. The virtual marks created by the motion and movement of the design were highlighted in the third dimension and built with a new cover system that merges with the ideas of fluidity and organicism. The upper cover was shaped to differentiate between registered and non-registered structures. The structures that go against the historical texture turned into an amorph shape, while a flat design that doesn't overshadow the registered structures was proposed. To hide the airconditioning units and electrical wiring which create an unappealing view and protect them from physical effects, a double-skinned design was chosen for the upper cover. The first layer is made of glass and it surrounds the entire bazaar. The steel structure that forms the second layer has flat areas in certain places as well as forming curves that become amorphised and pierce through the glass in others. Keeping the damage that could result from load bearing elements of the upper cover to registered structures in mind, load bearing elements were connected to unregistered structure $s$ on the middle axle of the bazaar. In the streets where there were only registered structures, horizontal load bearers were used (Figures 14 and 15).

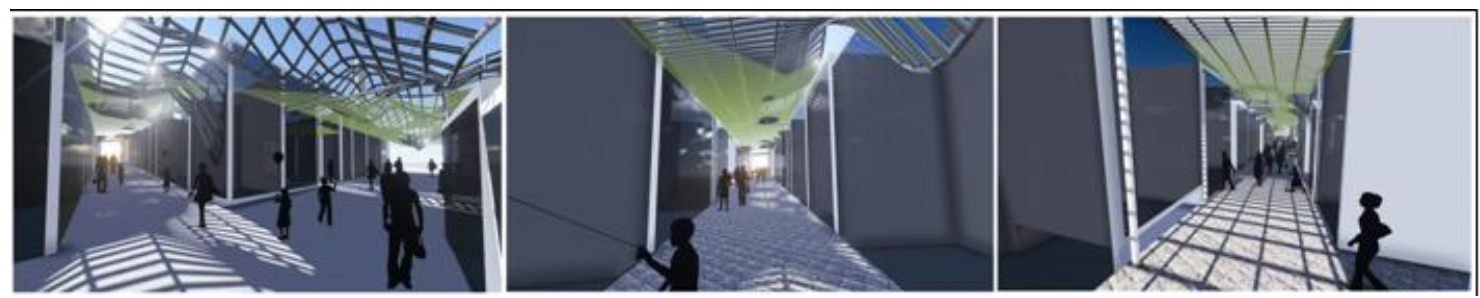

Figure 14. MASS 2015 first group's studies

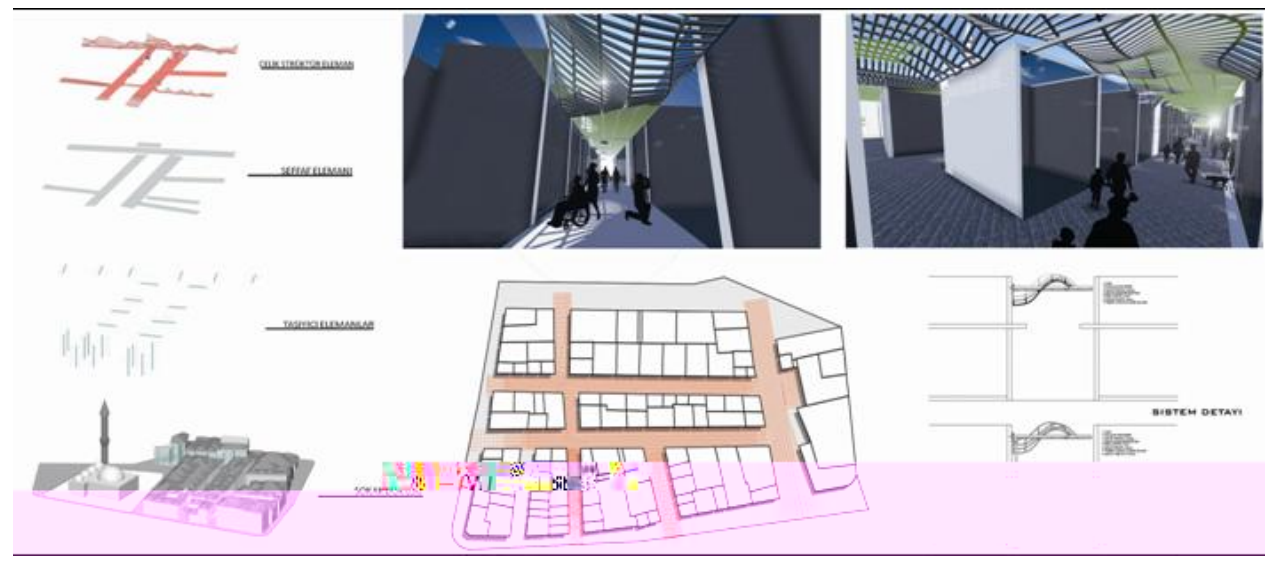

Figure 15. MASS 2015 first group's studies

\subsubsection{Group project report}

The design of the upper cover is based on the idea of renewable energy usage. Designed with steel and glass materials, upper covers were designed with photovoltaic panels. Hence, Uzum Pazari will have a modem upper cover installed and have its electricity needs supplied at the same time. Panels 
were also planned to be retractable. Therefore, it will be possible to retract the panels for the ventilation of the streets and allowing sunlight when needed. The use of vine-like plants to climb over the lower surface of the panels was considered. This way, the upper cover will have a green texture when viewed from Uzum Pazari streets and gain a pleasant look. The mixture of green texture with the stone materials of the bazaar, the windows and the glass look of upper cover will accentuate the traditional look of Uzum Pazari (Figure 16).
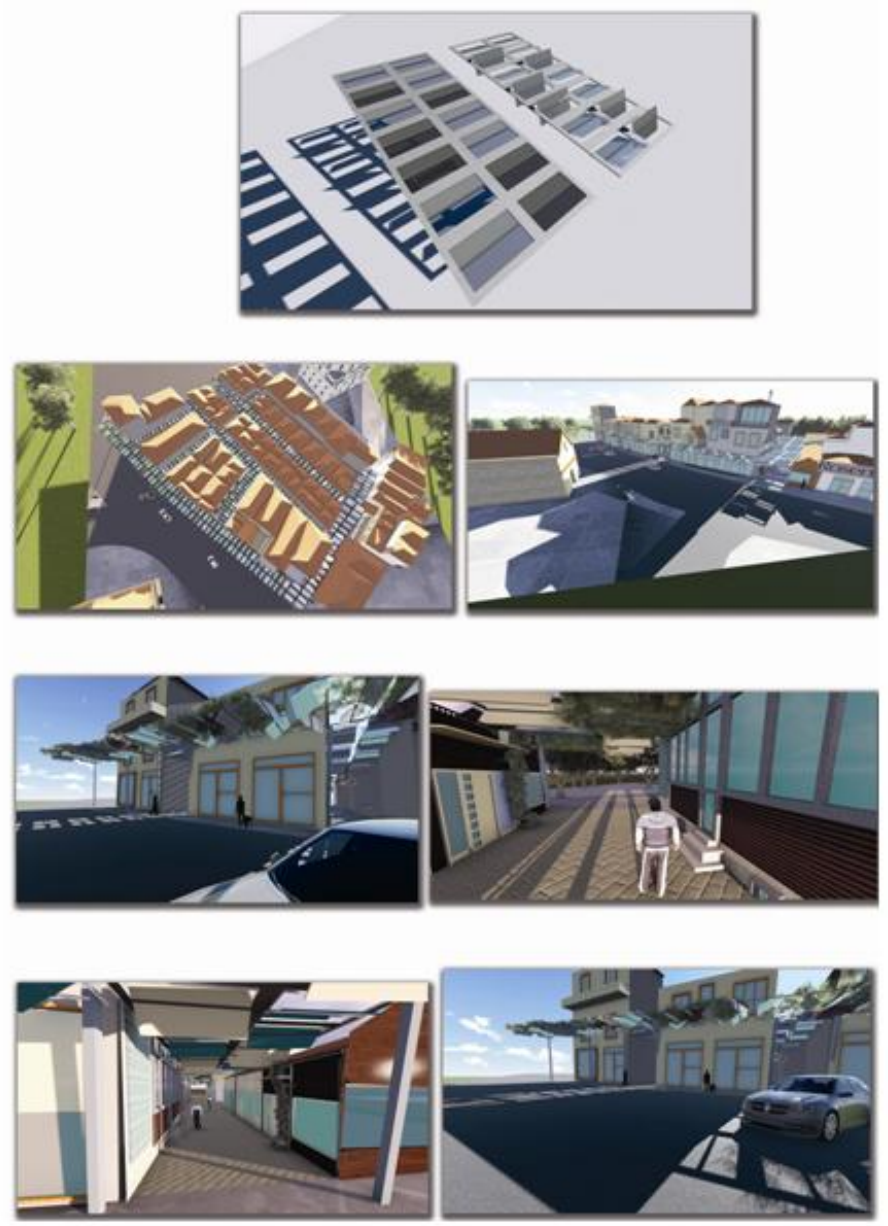

Figure 16. MASS 2015 second group's studies

\subsubsection{Group project report}

To avoid blocking the perception of historical structure, curved surfaces that rise and dip in different places were planned for the upper cover. For this surface, a load-bearing system that can provide its own vertical stability without creating additional strain for the structures is proposed. light materials like glass and steel are used in the structure. Furthermore, an emphasis has been put on the Karbuz Fountain, an important historical monument for Isparta that sits on the west side of Uzum Pazari. This fountain is a special place where people from Isparta and its visitors drank its water throughout its history. In our Uzum Pazari reorganisation project, we propose the construction of water canals that run through the middle of the bazaars streets. It's proposed that the starting point of these water canals should be Karbuz Fountain and the water that would be used for this canal should be from the fountain itself (Figure 17). 
Karakok, M. E. C. \& Gokarslan, A. B. (2018). A workshop experience in the intersection of design and conservation disciplines: Mediterranean architecture schools students' workshop. Global Journal of Arts Education. 8(1), 28-45.

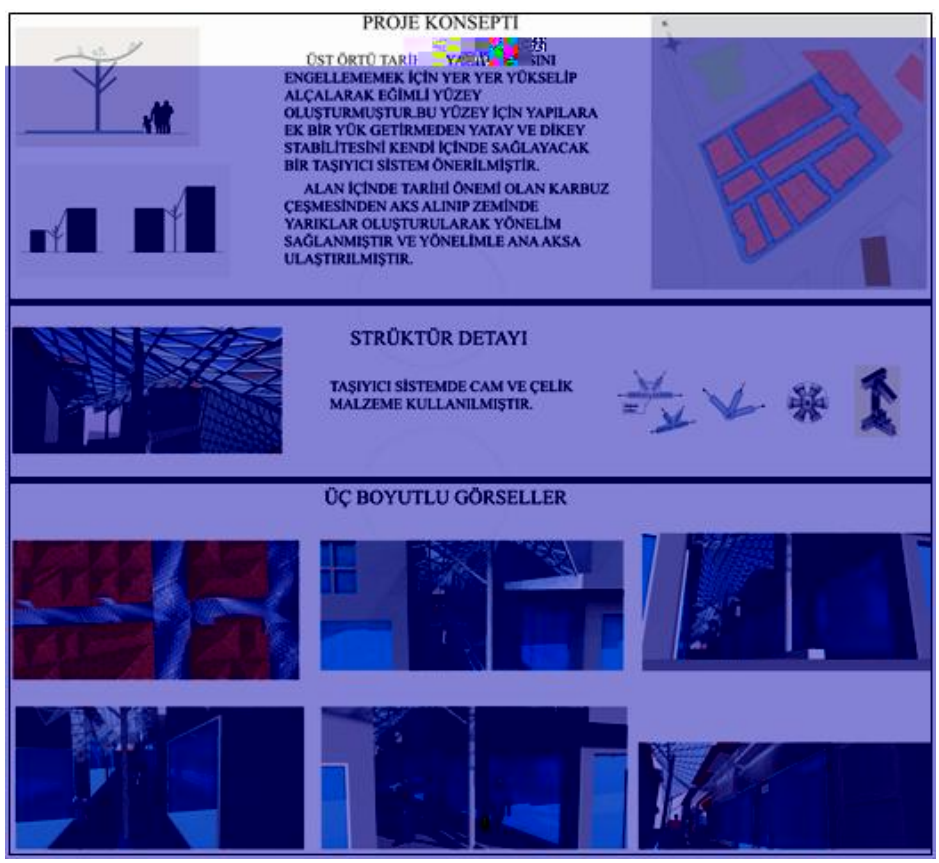

Figure 17. MASS 2015 third group's studies

\subsubsection{Group project report}

For the design of the upper cover, the abstraction of the traditional form of hipped roofs was used as a starting point. Triangle modules were created from the shapes of hipped roof forms using the method of abstraction. Made from steel structures and covered with glass, these triangle modules were placed against each other with $30^{\circ}$ angles. With spaces created by the angular placements of triangular modules, an air circulation was planned in between the streets (Figure 18).

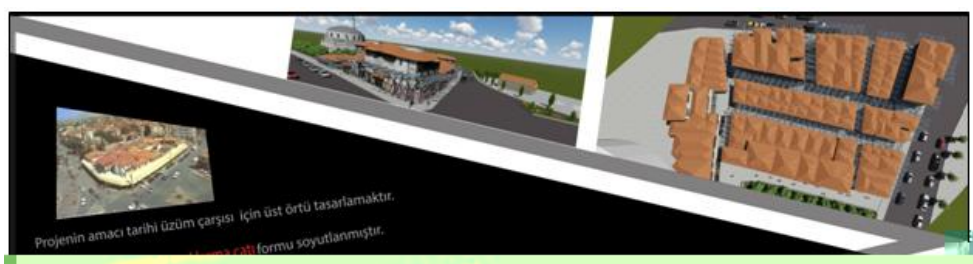

Figure 18. MASS 2015 fourth group's studies 


\subsection{Second workshop project: Koy Pazari project reports}

\subsubsection{Group project report}

The design of the upper cover is based on the idea of renewable energy usage. Polycarbonate sheets will be placed in semicircular form over the construction designed with galvanised steel. These polycarbonate layers were planned to have many small, moving solar panels located on the surf ace. This way, Koy Pazari will both have a modern upper cover; and also, supply its electricity from here. Polycarbonate sheets will also have lighting elements installed under the covers powered by the panels on the surface. Wooden stands will be installed on two different levels of the galvanised steel construction footings (Figure 19).

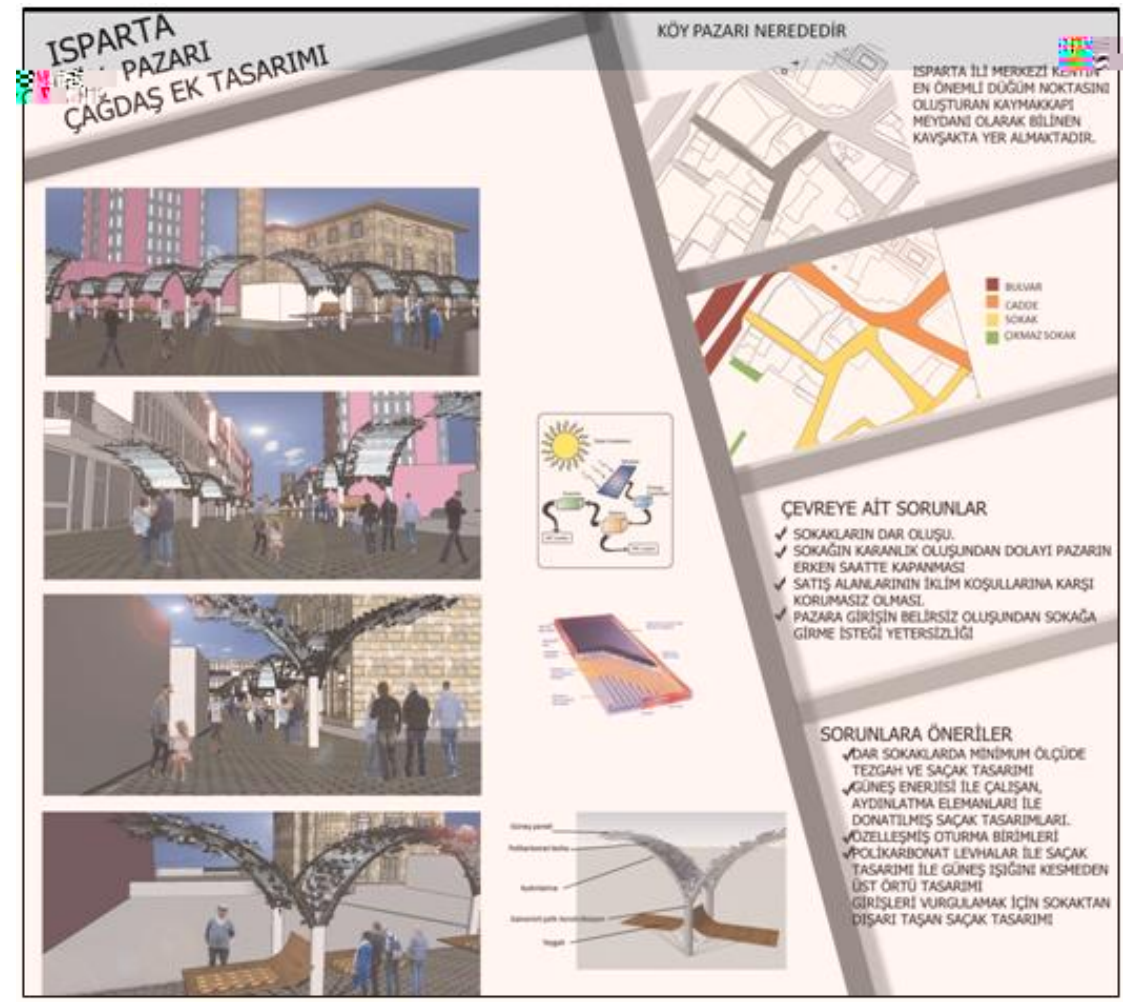

Figure 19. MASS 2015 fifth group's studies

\subsubsection{Group project report}

The design idea was based on 'the concepts of empty space and compact architecture'. The upper cover of the streets was planned to have circular spaces over a plate that has an organic form. With the help of these spaces, outside elements like sunlight and the air are aimed to be transferred both indoors and the streets of the bazaar. It was also planned to have evergreen trees in some parts of the streets where these spaces projected on and to let the trees grow over these spaces towards the sky. Therefore, the aim was to integrate a piece of nature to both the perception of the streets of Koy Pazari and its visual from outdoors. Construction footings of the upper cover on 1409 Street are placed on two sides of the street. Wooden stands were planned in front of the footings. To avoid blocking the view of historical structures on 1410 Street, only one footing has been placed on the middle axle of the street to bear the load of the construction. Also in these streets, stands were placed back to back on both sides of the footings (Figure 20). 


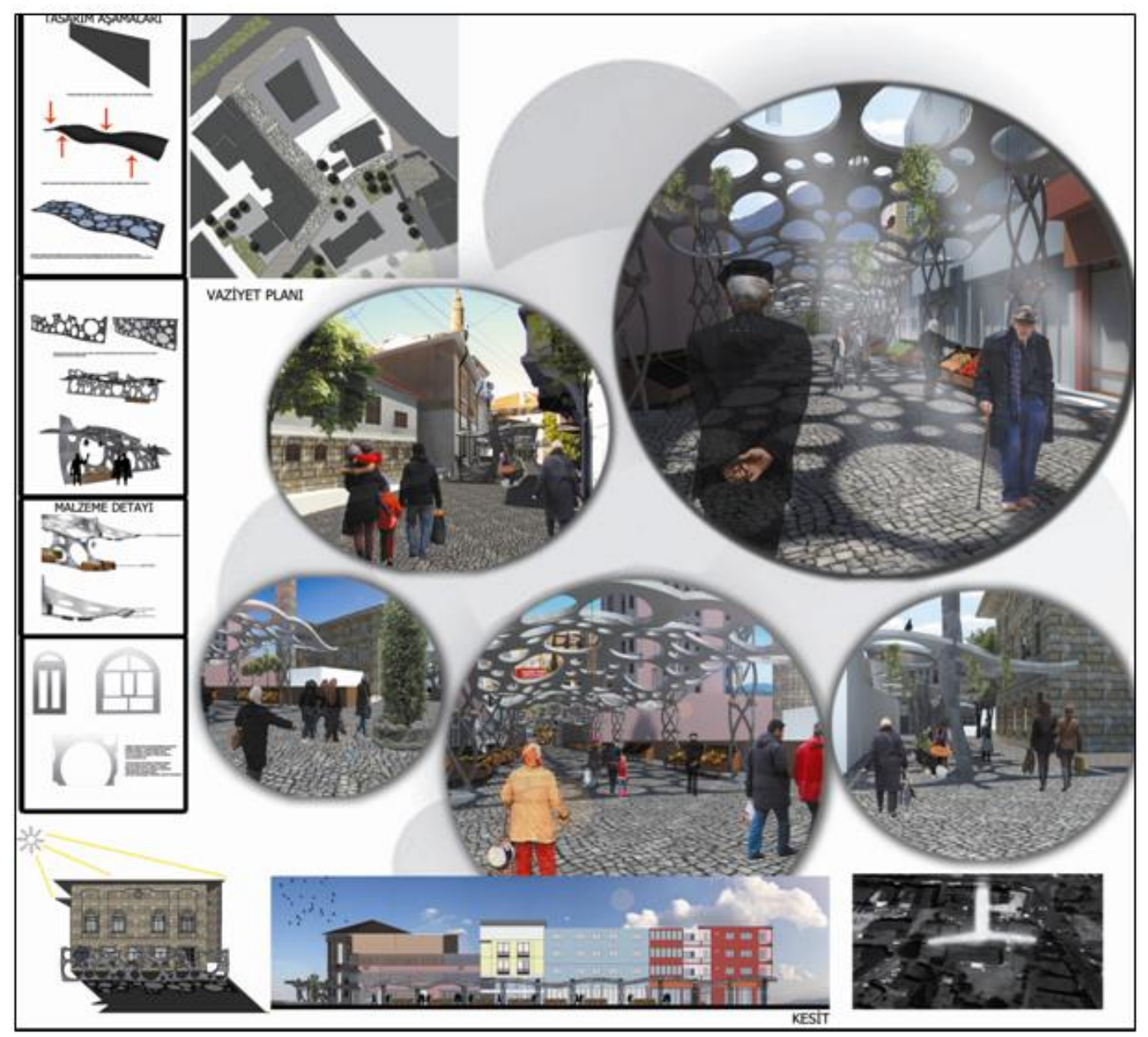

Figure 20. MASS 2015 sixth group's studies

\subsubsection{Group project report}

The design idea of the upper cover is inspired by the old bazaar tents and its dimensions were created by using the nearby historical buildings as a reference. Balance point and the centre of gravity between the membrane material and tensile structures are placed in bazaar areas that have the lowest foot traffic. To clear the passage of commercial units on 1409 Street, stalls of the sellers were placed around an axle that runs in the middle of the street. To avoid the stalls blocking the view of Iplikci Mosque caused by the narrow area of 1410 Street, stalls in the bazaar area were moved closer to modern day buildings. A change of use was planned for the rest of the street and the part in front of the Cumhuriyet Elementary School to prevent the noise coming from the bazaar interrupting the education in the school. This area was suggested to be used as a social area. where the school students can display their imagery work like paintings. The space located at the intersection of two streets is planned to serve as a small square. The upper cover was moved higher towards the square to have a better view of the square and Cumhuriyet Elementary School and to highlight the area (Figure 21). 


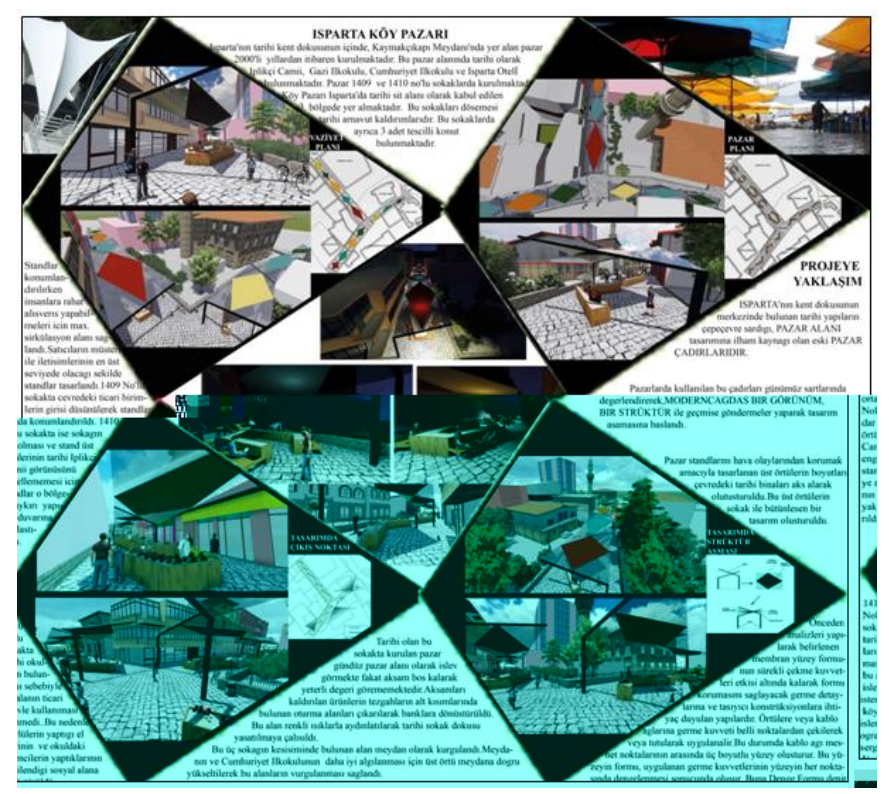

Figure 21. MASS 2015 seventh group's studies

\subsubsection{Group project report}

An amorph design is proposed for the upper cover. The aim was to create a morphological contrast between the modern addition and historical texture to highlight the stark contrast between the old and new. It was also planned to create an area that could be used for the service of the mosque and bazaar, clearing the facades of the buildings by moving the modern addition away from registered structures, and improving the streets by organising the current commercial use under residential structures. Greening and sitting benches were proposed for the area between Isparta Hotel and Iplikci Mosque. Within the scopes of concepts like locality and traditionality, a need for a historical texture and organic order was deemed to be necessary. That's why the upper cover is designed in a curvilinear form as much as the current linear scheme allows (Figure 22).
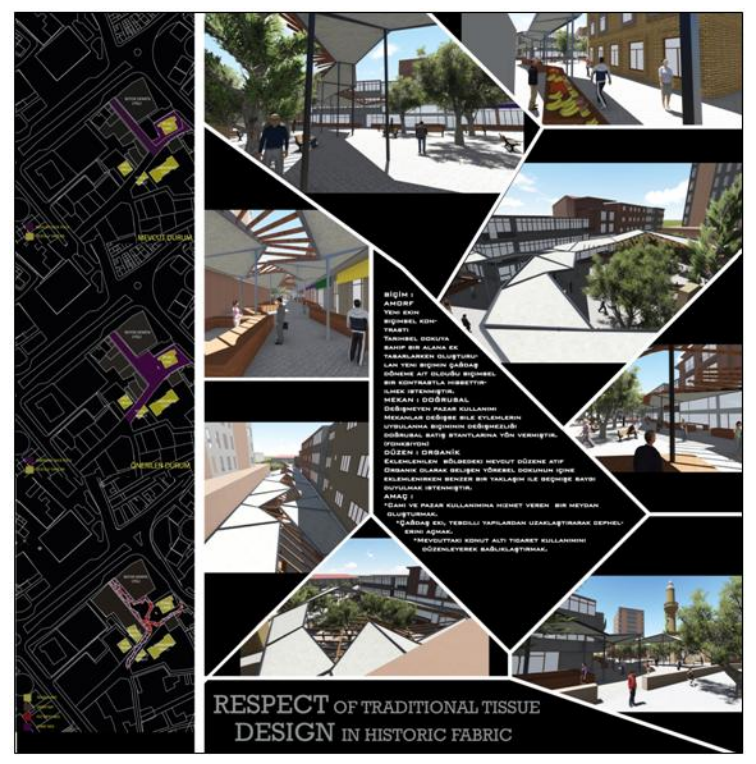

Figure 22. MASS 2015 eighth group's studies 
The subject of modern addition is usually covered in the courses of 'Restoration and Conservation' and 'Restoration Methods' in architectural schools of our country. It was observed that most of the students in both universities answered the questions correctly in their conservation and restoration mid-terms and finals, and this result was first interpreted as a success of the teaching method.

The subject of modern addition is explained in the courses 'conservation and restoration' and 'Restoration Techniques' in the architecture schools of our country. Within the scope of this course, students are briefly told that for the modern usage of historical textures and structures, an addition can be made due to newly arising needs. These additions can sometimes be a toll booth, toilet, a building and sometimes semi-open spaces like a terrace, gallery where it can also be used as indoor areas, sometimes an upper cover like a dome and overhang, or circulation elements like stairs, ramps, corridors, tunnels or elevators. It's highlighted that these additions cannot be built randomly and have to be designed carefully. A strong emphasis is put on the certain principles for the design of additional areas to historical places. These principles are explained as it should use modern materials, it shouldn't overshadow the historical building and that it shouldn't damage the aesthetical structure/purpose of the historical building. These talking points are supported by both domestic and international visual examples. And all of this information is thought to be adequate for the understanding of modern addition subject. Hence, the students from both universities mostly answered questions about modern additions correctly in both their theoretical exams and preworkshop refresher training.

However, when it comes to the execution stage of the workshop, in other words, the design and the planning stage of a modern addition in a historical context, it was observed that students hesitated and even demonstrated erroneous tendencies. During the projects, the students have often been warned by the executors of the workshop for their wrong interpretation of the concept of modern addition and have been told to stop their erroneous behaviour. The main erroneous behaviours of the students were using modern but concealing materials/structure forms, losing the scale by overloading the historical structure and trying to integrate objects like antique columns, arches and pediments to their designs.

Despite the fact that courses and presentations of conservation and restoration are supported with many visuals and many of the students correctly answer the questions in theoretical exams, it was understood that the students do not have an accurate and clear image of the subject. The need for projects that directly involve the students in the process and building three-dimensional models of these projects to make them visualise the results are understood to be necessary to provide the accurate and complete information to students. Although the courses that contain the subjects of conservation and restoration are considered as classes that can be taught theore tically in short course hours, these courses have to be transformed into classes with longer hours that have applied components.

The discipline of conservation and restoration is considered an area of speciality for postgraduate education. However, it should also be noted that students have the authorisation to undertake conservation and restoration projects and their execution after they get their undergraduate diplomas and that they are very likely to create new, modern additions in a historical texture in their professional life. Therefore, it's important for architecture students to be equipped as much as possible with the knowledge and skills about this discipline before they complete their undergraduate education. This necessity is crucial for both quality architectural education and for better preservation in the projects and applications of our architects and handing our immovable cultural assets down to next generations. 
Karakok, M. E. C. \& Gokarslan, A. B. (2018). A workshop experience in the intersection of design and conservation disciplines: Mediterranean architecture schools students' workshop. Global Journal of Arts Education. 8(1), 28-45.

Antalya Cultural and Natural Heritage Preservation Board 10.11.2006 dated and 1303 numbered decision. Antalya Cultural and Natural Heritage Preservation Board 13.12.2007 dated and 2010 numbered decision. Antalya Cultural and Natural Heritage Preservation Board 27.03.2008 dated and 2261 numbered decision. Antalya Cultural and Natural Heritage Preservation Board 28.07.1992 dated and 1495 numbered decision. Bocuzade, S. S. (1983). Isparta tarihi. Istanbul, Turkey: Serenler Press.

Demirgil, S. (2007). Mazideki Isparta-1. Isparta, Turkey: Isparta Municipality Publishing. Isparta Municipality Archive. (2014).

Isparta Governship. (2001). Isparta 1880-1980. Isparta, Turkey: Special Provincial Directorate of Administration Publishing.

Suleyman Demirel University. (2015). Isparta, Turkey: Department of Architecture, Conservation Course Works. 